\title{
Summary of Credit Risk Assessment Methods
}

\author{
Qiang Cai ${ }^{1,2}$ and Qian Qian ${ }^{2}$ \\ ${ }^{1}$ Macro Economy and Finance Research Center, Sichuan Radio and TV University \\ ${ }^{2}$ School of Management and Economics of UESTC
}

\begin{abstract}
It is the forefront research direction for credit risk management field to explore the theory and method of social-economic entity credit characteristics evaluation, improve and deepen the market-economy entity credit evaluation system. The paper improves various "modern" credit risk evaluation modes based on "traditional" credit risk evaluation models combined with credit risk concept and classification as well as credit risk evaluation methods. From overseas scholars' literature achievements to domestic scholars' latest research, the paper makes a full exploration and analysis. It evaluates American credit managers index, world bank credit information index, China credit well-off index and other typical credit indexes.
\end{abstract}

\section{Keywords—credit risk; credit index; evaluation model}

\section{INTRODUCTION}

Market economy development shall undergo a process from disorder to order. It shall be credit economy when it reaches the advanced form. Lower-income consumers can use credit to buy houses, cars and other commodities via mortgage or other financial policies. Enterprises with good credit can get more capitals and market opportunities. Trade market can achieve healthy and continuous development. Finally it contributes to the development of the economy as well as the whole society. So market economy and finance can not leave credit if they develop further. Credit plays a role of lubricant in social and economic development. In other words, credit is the foundation stone of modern social economic development. Social credit system shall contribute to Chinese social economic development.

Social Credit System Construction Planning Outline (2014-2020) (National Development and Reform Commission (2014) No. 21) defined the meaning of social credit system clearly: the sound social credit system can guarantee the healthy operation of market economy and improve Chinese citizens' credit awareness. Economic entity credit evaluation system is an important part of social credit system construction. Credit evaluation system needs scientific, effective methods and means. For this, the paper summarizes credit risk evaluation methods to help the long-term effective development of credit risk management technology.

\section{CREDIT RISK AND EVALUATION}

The common credit risk can be defined in two ways: generalized credit risk and narrow-sensed credit risk. Generalized credit risk refers to the possibility of the loss caused by counterparty's credit default. Under this definition, the risk of various credit trades can be called credit risk. For the two parties which have credit debt relation, the borrower's dishonest conduct makes the lender suffer the loss risk. It can be called narrow-sense credit risk. For commercial banks, credit\&loan customers' promise, fund use and repayment of principal and interest etc shall be faced with risk ${ }^{[1]}$.

Credit risk evaluation refers to that financing institutions (like commercial banks) or credit evaluation institutions evaluate the evaluation target's contract fulfillment ability and credibility to define the evaluation target's credit grade. At present, the two risk evaluation methods ("traditional" and "modern" methods) are widely used in the academic world and the industry. The evaluation method used by commercial banks and other financial institutions to have a qualitative analysis on customers based on previous experience shall be called "traditional" credit risk evaluation. Most of these theories and methods are accumulated by commercial banks in their credit lending practice. With the rapid development of computer and other auxiliary computing tools, financial engineering, mathematical knowledge and other theory knowledge and models make it easy to have quantitative evaluation on customers' credit risk. The method is called "modern" risk evaluation method.

"Traditional" credit risk evaluation model is easy to operate, but the evaluation model depends on experts or the estimators' subjective judgment too much. So it may lead to erroneous judgement. It is scholars' target to find more objective and precise credit risk evaluation methods. In enterprise financial data, Beaver (1966) ${ }^{[2]}$ found the single variable index (used for default standard judgement) via comparative analysis. However, predicted results are not accurate enough, so many scholars improve model addition variables to get a series of multivariable prediction models based on single variables. Z-scoring model established by $\operatorname{Altman}(1968)^{[3]}$, an American finance scholar, is kind of famous and popular. Later, Altman(1977) $)^{[4]}$ improved the original model. After replacing and adding two new indexes, Altman got the improved Zeta-scoring model with seven indexes. The linear discriminant model established by Gowberger (1964) ${ }^{[5]}$ is the earliest credit risk evaluation multivariable model.

With the continuous development of mathematical statistics, Probit model ${ }^{[6]}$ and Logistic model ${ }^{[7]}$ are made and widely used for default forecasts of credit\&loan customers. Logistic model is also used for evaluation of financial institution default probability by West $(1985)^{[8]}$.

Since sample data is unavailable or sample quantity is too small etc, the statistic method is no longer applicable. A method which does not depend on data shall be explored. Therefore, projection tracing decision method ${ }^{[9]}$, data envelope method $^{[10]}$ and other non-statistic methods shall emerge at the 
right moment. With the rapid development of artificial intelligence technology, some theories and methods are used in credit\&loan customer credit risk evaluation, including genetic algorithm model ${ }^{[11]}$, support vector machine model ${ }^{[12]}$, neural network model ${ }^{[13]}$, clustering model ${ }^{[14]}$ and rough set model ${ }^{[15]}$. The corresponding evaluation model is established.

Credit risk may come from enterprise value change. Scholars tried to estimate its occurrence possibility from credit risk occurrence source. From this perspective, the structured model established the credit risk evaluation model. Based on Black-Scholes-Merton options pricing formula ${ }^{[16]}$, Merton(1974) $)^{[17]}$ established the structured model of credit risk evaluation. The evaluation of enterprise asset value and volatility is the core of the model. Jones and Scott (1984) etc ${ }^{[18]}$ used other methods to estimate enterprise asset value. Ronn and Verma(1986) ${ }^{[19]}$ estimated the company value $V_{t}$ and volatility $\sigma$ when obeying Brownian movement hypothesis in enterprise rights and interests value. In the structured model, the enterprise may breach the contract only when the debt expires. But in the reality, the enterprise may break the contract anytime. Blade and $\operatorname{Cox}^{[20]}(1976)$ eased the hypothesis and got the default model for the first time. Since some hypotheses are harsh (risk-free interest rate is fixed, company asset value is continuous diffusion and there only exist stocks and bonds in the enterprise), it limits the use range of structured model. Based on the model, scholars got the improved structured model after eliminating or easing some hypothesis conditions. Hypothesis interest rate change of Longstaff and Schtrwartz $(1995)^{[21]}$ met the interest rate model of Vasicek(1977) ${ }^{[22]}$. They improved the structured model and eased the hypothesis of interest rate term structure invariability. According to the structured model, the company default is influenced by its asset value. Namely, default event is influenced by endogenous factors. But some scholars think the default has nothing to do with the company asset value. Jarrow and Turnbul (1995) ${ }^{[23]}$ thought the enterprise default was a random event and was totally influenced by exogenous factors. From this perspective, asset value change is a continuous diffusion process and the default is under a random hypothesis condition. Jarrow etc $(1997,1999)^{[24-25]}$ made a series of work and got a simplified model. The model used the default time to evaluate the enterprise credit risk. In the simplified model, Poisson random process shall record the default time.

The default times refer to the default probability under the Poisson process or non-Poisson process hypothesis. As for default strength $\lambda(u)$, $\operatorname{Lando}(1998)^{[26]}$, Duffee $(1999)^{[27]}$, $\mathrm{Yu}(2003)^{[28]}$, Duffie and Garleanu(2001) ${ }^{[29]}$ and Kay(2003) ${ }^{[30]}$ etc did a lot of researches from default strength random process and influence factors.

When the information was incomplete, Duffie and Lando(2001) ${ }^{[31]}$ combined the structured model with the simplified model for the first time. Cetia and Jarrow(2004) ${ }^{[32]}$, Giesecke(2006) ${ }^{[33]}$, Giesecke and Goldberg(2003) ${ }^{[34]}$, Jarrow and Protter(2007) ${ }^{[35]}$, Jeanblanc and Valchev(2007) ${ }^{[36]}$ and $\operatorname{Guo}(2005)^{[37]}$ etc did a lot of relevant work in combining the structured model with the simplified model. Ctin (2012) ${ }^{[38]}$, Hainaut and Robert (2014) etc ${ }^{[39]}$ inset the incomplete information into structured model and simplified model to measure credit risk.

After borrowing foreign scholars' research results, domestic scholars did a lot of researches on credit risk evaluation. Dai Zhifeng $(2015)^{[40]}$ used Chinese listed companies' and commercial bank non-listed companies' data to have an adaptive analysis on the non-listed companies' risk measurement model based on options pricing. Based on structural equation, Chen Xiaohong etc $(2008)^{[41]}$ had an empirical analysis on the relation of Chinese middle-and-small enterprises' growth and bond governance mechanism. Dong Naiquan (2010) ${ }^{[42]}$ compared and analyzed the veracity of Merton model and Leland-Toft model. The empirical analysis showed Leland-Toft model was more effective. Combined with jump diffusion model and options pricing ideas, Tang Qiming and Huang Ran (2010) ${ }^{[42]}$ considered the jump risk influence of enterprise asset value when evaluating enterprise credit risk. Han Liyuan etc (2012) ${ }^{[44]}$ got the bond default probability under the variable variance condition based on option pricing. They found further that there existed the negative correlation between default probability and risk-free interest rate. Zhou Hong and Li Guoping etc (2015) ${ }^{[45]}$ compared and analyzed structural model, strength model and mixed model from different perspectives. Logistic model and SVM model were used by commercial credit to evaluate individual credit\&loan customers ${ }^{[46-47]}$. Based on data mining method, Xiao Chaowu etc $(2014)^{[48]}$ used random forest combination classification model to evaluate and predict the credit\&loan customer risk of commercial banks. Yang Fan etc (2016) ${ }^{[49]}$ used rough set and support vector mechanism to establish credit evaluation RS-SVM complex model. They used the data of building enterprises to inspect the effectiveness and veracity of model. Wang Xiongyuan and Gao Kaijuan (2017) ${ }^{[50]}$ studied how customer concentration had an influence on bond risk. The empirical analysis showed that customer concentration had a risk effect on the bond investors. For the credit risk evaluation of supply chain finance and P2P special background, a lot of scholars started to carry out a research on it. Yi Xuehui $(2011)^{[51]}$ studied how to design a contract agreement to bind supply chain core enterprises with middle-small enterprises credit based on the perspective of commercial banks. This way it could get commercial banks' repurchase guarantee to the core enterprises. Hu Haiqing etc $(2014)^{[52]}$ set up the middle-and-small enterprise credit risk evaluation index system in supply chain finance. They used SVM to evaluate. Zhou Wenkun etc $(2015)^{[53]}$ also set up a set of complete evaluation index system and used DEA, AHP and fuzzy TOPSIS method to evaluate the middle-and-small enterprise credit risk on the supply chain. Fu Bin $(2017)^{[54]}$ analyzed the risk features of supply chain financing from the perspective of banks and set up the middle-and-small enterprise credit risk evaluation index system. Emekter $(2015)^{[55]}$ used the data on Prosper, Lendingclub and other platforms and conducted empirical analysis on the individual credit\&loan customer risk on P2P platform. At the same time, data mining, SVM and neural network and other credit risk evaluation methods were used by domestic and foreign scholars to evaluate credit risk under P2P background. For example, Malekipirbazari $(2015)^{[56}$ etc established individual credit risk evaluation model based on random forest classification method. Li Shujin etc (2016) 
[57] used network loan data to compare BP neural network and Logistic regression model. They found that BP neural network model had a more accurate evaluation. Xu Huiting (2016) ${ }^{[58]}$ started from P2P platform credit risk to set up the borrower credit evaluation index system with the research purpose of borrower risk control. He used the data on American P2P network loan platform -- Prosper to establish borrower credit risk evaluation model based on Logistic regression. Li Xin etc (2018) ${ }^{[59]}$ established the borrower credit risk evaluation index system based on P2P Internet loan features. They set up Internet loan borrower risk evaluation model based on neural network model. Besides, Li Yichao etc $(2015)^{[60]}$ studied the local credit risk and analyzed the government risk control strategy. Lai Hui etc (2017) ${ }^{[61]}$ used C2C model to analyze network credit influence factors and set up the credit risk evaluation model based on network credit. $\mathrm{Hu}$ Xiande etc $(2017)^{[62]}$ got a new kind of IDGSO-BP algorithm based on GSO algorithm. The algorithm could estimate the credit risk of macro-and-small enterprises precisely. With the rapid development of computer relevant technology, the financial data analysis method is also used credit risk evaluation ${ }^{[63-65]}$.

\section{CREDIT INDEX}

Since Zou Fangli (2011) ${ }^{[66]}$ proposed credit index, it has been used in many fields. There are some famous ones, like American credit managers index, world bank credit information index, Chinese urban commercial credit environmental index $(2013)^{[67]}$, Chinese export credit insurance company trade credit risk index $(2012)^{[68]}$. So credit index is so wide, including individual, enterprise, industry, country and many aspects. There are some typical ones as follows.

\section{A. NACM Credit Managers Index}

Credit Managers Index (CMI) was established by National Association of Credit Management in the middle of the $20^{\text {th }}$ century. It is used to inspect macro economy from the perspective of commercial credit and commercial loan collection. The enterprise credit manager evaluates the enterprise business operation situation every month based on the relevant index. Credit Managers Index comes from the summary of the operation situation. Compared with western developed countries, Chinese market economy is still at the exploratory stage and is not mature. So it is not suitable to adopt CMI index withdrawal method to set up indexes now in China. But with the development of social economy, CMI whose withdrawal way is economic index can be considered to adopt.

\section{B. World Bank Credit Information Index}

Since 2003, world bank has published Global Commercial Environmental Report based on years. Report shows the ranking of over 170 countries and areas in the commercial environment. Report is based on the quantitative index of a series of government evaluation standards and its implementation situation. One of these indexes is called credit information index. It is to test the difficulty that national or regional credit reporting agency collects information. The difficulty grades are 0 to 6 from low to high. If the number is bigger, it means that the national credit reporting agency collects more information and the information is more valuable.

\section{China Credit Well-off Index}

China credit well-off index was set up by Well-Off periodical office China comprehensive well-off research center and Tsinghua University media research laboratory to examine the comprehensive index of China credit situation. The credit index is to carry out the evaluation work from three aspects: first, it aims at examining the government credibility; second, it aims at examining the personal credit; finally, it aims at examining the enterprise credit, namely, whether enterprises fulfill relevant functions and obligations according to national policy. The three aspects above account for $40 \%$, $30 \%, 30 \%$ respectively.

\section{Yiwu Market Credit Comprehensive Index YMCI (2009)[69]}

Yiwu market credit index was compiled by Zhejiang administration for industry and commerce, Yiwu people's government and China credit research center of Peking University. It is the first regional credit index. It covers eight kinds of indexes, namely, credit management index, operation potential index, performance development index, financing credit\&loan index, equal competition index, commodity quality index, knowledge intellectual property index and consumers' rights protection index. YMCI, a first regional credit index in China, can build the confidence for other regions of China to search for information and set up credit index. At the same time, it can help to guide other regions.

\section{CONCLUSION}

At present, China market economy has entered an advanced stage -- credit economy. Economic activities on the market are related to the economy entity credit. Therefore, credit has played a lubricant role in economic development. Especially, with the rapid development financial market, credit becomes the "fortune" of economy entity. Furthermore, credit contributes to the development of the modern social economy and creates more employment opportunities. Finally it contributes to the development of the the whole society, economic prosperity and development. The paper sorts out and summarizes the credit risk evaluation method to provide reference for the development and application of credit risk management technology.

\section{ACKNOWLEDGEMENT}

National Natural Science Foundation of China "Research on the Formation Mechanism of Electricity Pricing Mechanism of Renewable Energy Sources" (71473031); Sichuan key program of basic research for application "Research on Electricity Pricing Formation Mechanism in Diversified Energy Structure" (2017 JY0200); 2016 topic "Research on the System of Market Subject Credit Evaluation in Sichuan" (SC16B049) in "the 13th Five-Year Plan" of Sichuan social sciences research.

\section{REFERENCES}

[1] Fan Xiaopin, Wu zhonglun. Integrity, trust, credit concept and relation analysis [J]. Technology economy and management research, 2005(1):98-99.

[2] W. H. Beaver. Financial Ratio as Predictors of Failure[J]. Journal of 
Accounting Research, 1966, 4: 71-111.

[3] E. I. Altman. Financial Ratios Discriminant Analysis and the Prediction of Corporate. Bankruptcy[J]. Journal of Finance, 1968, 23(4): 589-609.

[4] E. I. Altman, N. Haldeman. ZETA Analysis: A New Model to Identify Bankruptcy Risk of. Corporations[J]. Journal of Banking and Finance, 1977, 1: 29-54.

[5] A. S. Goldberger. Economic Theory[M]. New York: John Wiley \& Sons, 1964.

[6] D. Martin. Early Warning of Bank Failure: A Logit Regression Approach[J]. Journal of Banking and Finance, 1977, 2: 249-276.

[7] J. S. Ohlson. Financial Ratio and the Probabilistic Prediction of Bankruptcy[J]. Journal of Accounting Research, 1980, 19: 109-131.

[8] R. C. West. A factor-analytic approach to bank condition[J]. Journal of Banking \& Finance, 1985, 9(2):253-266.

[9] P. J. Huber. Projection Pursuit[J]. Ann. Statist, 1985, 13(2): 435-475.

[10] B.W. Porter, R. Bareiss, C. Holter. Concept learning and heuristic classification in weak- theory domains $[\mathrm{J}]$. Artificial Intelligence, 1990,45(1):229-263.

[11] F. Varetto. Genetic Algorithms Applications in the Analysis of Insolvency Risk[J]. Journal of Banking and Finance, 1998, 22: 1421-1439.

[12] L. A. Yu, S. Y. Wang, et al. A modified least squares support vector machine classifier with application to credit risk analysis [J]. International Journal of Information Technology and Decision Making, 2009,8(4): 697- 710.

[13] E. C. Arzum, Y. Karatepe. Evaluating and Forecasting Banking Crises Through Neural Network Models: An Application for TURKISH Banking Sector[J]. Expert Systems with Applications, 2007, 11:809-815.

[14] M. Lundy. Cluster Analysis in Credits Coring: Credit Scoring and Credit Control[M]. New York: Oxford University Press, 1993.

[15] Z. Pawlak. Rough Sets[J]. International Journal of Information and Computer Science, 1982, 11:341-356.

[16] F. Black, M. Scholes. The pricing of options and corporate liabilities[J]. The Journal of Political Economy, 1973(5): 637-654.

[17] R. C. Merton. On the pricing of corporate debt: The risk structure of interest rates[J]. The Journal of Finance, 1974, 29(2): 449-470.

[18] E. P. Jones, P. M. Scott, E Rosenfeld. Contingent Claim Analysis of Corporate Capital Structures: An Empirical Investigation[J]. Journal of Finance, 1984, 39(3): 611-625.

[19] E. I. Ronn, A. K. Verma. Pricing Risk-Adjusted Deposit Insurance: An Option - Based Model[J]. Journal of Finance, 1986, 41(4): 871-895.

[20] F. Black, J. C. Cox. Valuing Corporate Securities: Some Effects of Bond Indenture Provisions[J]. Journal of Finance, 1976, 31(2): 351-361.

[21] F. A. Longstaff, E. S. Schwarts. A Simple Approach to Valuing Risky Fixed and Floating Rate Debt[J]. Journal of Finance, 1995, 50(3): 789-819.

[22] O. Vasicek. An Equilibrium Characterization of the Term Structure[J]. Journal of Financial Economics, 1977, 5: 177-188.

[23] R. A. Jarrow, S. Turnbull. Pricing Derivatives on Financial Securities Subject to Credit Risk[J].Journal of Finance, 1995, 50(1): 53-86.

[24] R. A. Jarrow, D. Lando, S Turnbull. A Markov Model for the Term Structure of Credit Risk Spreads[J]. Review of Financial Studies, 1997, 10: 481-523.

[25] R. A. Jarrow. Estimating Recovery Rates and Pseudo Default Probabilities Implicit in Debt and Equity Prices[J]. Financial Analysts Journal, 1999, 57: 75-92.

[26] D. Lando. On cox processes and credit risky securities[J]. Review of Derivatives Research, 1998, 2(2-3):99-120.

[27] G. R. Duffee. Estimating the Price of Default Risk[J]. Review of Financial Studies, 1999, 12: 197-229.

[28] F. Yu. Default Correlation in Reduced Form Models[J]. Journal of Investment Management, 2003, 3: 33-42.

[29] D. Duffee, N. Garleanu. Risk and Valuation of Collateralized Debt Obligation[J]. Financial Analyst's Journal, 2001, 57(1): 41-59.

[30] G. Kay. A Simple Exponential Model for Dependent Default[J]. Journal of Fixed Income, 2003, 13(3): 73-83.
[31] D. Duffee, D. Lando. Term Structure of Credit Spreads with Incomplete Accounting Information[J]. Econometrica, 2001, 9(3): 633-664.

[32] U. Cetin, R. A. Jarrow, P. Protter. Modeling Credit Risk with Partial Information[J]. Annals of Applied Probability, 2004, 14(3): 1167-1178.

[33] K. Giesecke. Default and Information[J]. Journal of Economic Dynamics and Control, 2006, 30(11): 2281-3303.

[34] K Giesecke, L Goldberg. Sequential Default and Incomplete Information[J]. Journal of Risk, 2004, 7(1): 1-26.

[35] R. A. Jarrow, P. Protter, A. D. Sezer. Information Reduction via Level Crossing in a Credit Risk Model[J]. Finance and Stochastics, 2007, 11(2): 195-212.

[36] M. Jeanblanc, S. Valchev. Default-risky bond prices with jumps liquidity risk and incomplete Information[J]. Finance and Stochastics, 2007, 11(2):195-212.

[37] X. Guo, R. A. Jarrow, Y. Zeng. Information Reduction in Credit Risk Models[J]. Mathematics of Operations Research, 2005, 2009, 34(2): 320-332.

[38] U. Çetin. On absolutely continuous compensators and nonlinear filtering equations in default risk models[J]. Stochastic Processes and Their Applications, 2012, 122(11): 3619-3647.

[39] D. Hainaut, C. Y. Robert. Credit risk valuation with rating transitions and partial information[J]. International Journal of Theoretical and Applied Finance, 2014, 17(07): 1450046.

[40] Dai Zhifeng, Zhang Zongyi, Chen Yinzhong. Research on Chinese non-listed company credit risk measurement based on options pricing theory [J]. Management science, 2005, 18(6):72-77.

[41] Chen Xiaohong, Wang Xiaoding, Zeng Jianghong. Creditor's rights governance mechanism, enterprise features and growth -- experimental evidence from China middle-and-smal companies[J]. Journal of management engineering, 2008, 22(4):19-24.

[42] Dong Naiquan. Empirical comparison study on listed company credit risk measurement model [J].Management review, 2010, 22(1):22-28.

[43] Tang Qiming, Huang Ran. Measurement and analysis of Chinese listed company default risk -- jump diffusion model application[J]. Quantitative economics technology research, 2010, 10: 101-115.

[44] Han Liyuan, Gu Zhihui, Ding Xiaopei. Credit risk measurement under the variable variance condition[J]. Journal of system engineering, 2012, 27(5):633-640

[45] Zhou Hong, Li Guoping, Lin Wanfa, Wang Yuan. Analysis and process of enterprise bond credit risk pricing model[J]. Journal of management science, $2015,18(8): 21-30$.

[46] Tang Haolong, He Bingquan, Zhou Wei. Credit\&loan agency individual loan credit evaluation model research based on SVM[J]. Western economic management BBS, 2012, 23(1):45-51.

[47] Pang Sulin, Gong Jizhang. C5.0 sorting algorithms application in credit\&loan agency individual credit rating $[\mathrm{J}]$. System engineering theory and practice, 2009, 29(12):94-104.

[48] Xiao Chaowu, Cai Wenxue, Huang Xiaoyu, Chen Kang. Individual credit evaluation model research and empirical analysis based on random forest[J]. Management science, 2014, (6):110-113.

[49] Yang Fan, Tan Fei, Cui Xiang. Building enterprise credit risk evaluation research based on RS and SVM [J]. Journal of Wuhan University of Technology, 2016, 38(1):537-540.

[50] Wang Xiongyuan, Gao Kaijuan. Credit spread between customer concentration and company bond secondary market [J].Finance research, (1):130-144.

[51] Yi Xuehui, Zhou Zongfang. Inventory pledge financing bank credit decision-making mechanism of double Stackelberg game[J]. System engineering, 2011 (12):1-6.

[52] Hu Haiqing, Zhang Lang, Zhang Daohong. Middle-and-small enterprise credit risk evaluation research from the perspective of supply chain finance -- comparison research based on SVM and BP neural network[J], Management and control review 012, 22(11): 70-80.

[53] Zhou Wenkun, Wang Chengfu. Middle-and-small enterprise credit risk evaluation research under supply chain financing mode -- based on left-right fuzzy TOPSIS algorithm[J]. Operation and management, 2015 (1): 209-215. 
[54] Fu Bin. Middle-and-small enterprise financing risk evaluation from the perspective of supply chain[J].Communication of finance and accounting, 2017(14):108-112.

[55] Li Shujin, Lu Jingqiang. P2P Internet loan borrower credit risk evaluation based on BP neural network[J]. Productivity research2016, (4):45-49.

[56] Xu Huiting. P2P Internet loan borrower credit risk evaluation research based on Logistic[J].Journal of China University Of Petroleum, 2017, 33(6): 16-20.

[57] Li Xin, Dai Yicheng. P2P Internet loan borrower credit risk evaluation research based on BP neural network [J]. Wuhan finance, 2018, (2):33-37.

[58] Li yichao, liao zhiling, du yicheng. Local government credit risk evaluation and countermeasure based on matter-element extension model[J].Economic Survey, 2016,33:33-138.

[59] Lai Hui, Huang Yumeng, Zhou Zongfang. Internet trust and Internet trade credit risk evaluation research based on cloud model -- a case study of C2C trade mode[J].Management review, 2017, 29(7): 225-233.

[60] Hu Xiande, Cao Rong, Li Jingming etc. Research on small-micro enterprise credit risk evaluation IDGSO-BP integrated model construction [J], Operation and management 2017, 26(4):132-148.

[61] Zou Fangli. Comparison research on domestic and foreign credit index compilation method[J].Credit investigation. 2011, (3):10-12.

[62] China commercial credit environment index (CEI) research group. 2013 China urban commercial credit environment index [M].Beijing: Beijing Yanshan Press, 2013.

[63] Ai Renzhi, Chen Yin, Cai Zhenggao. China short-term export trade credit risk index (2012) ERI[M]. Beijing: China Economic Publishing House, 2012.

[64] Zhejiang administration for industry and commerce, Yiwu people's government and China credit research center of Peking University. Yiwu market credit index development report [Z]. Beijing: China Economic Publishing House, 2009. 